\title{
INSIGHTS
}

\section{Family reflections: Hirschsprung disease}

\author{
Elizabeth Crawford ${ }^{1}$ \\ Pediatric Research (2019) 86:542-543; https://doi.org/10.1038/s41390-019-0361-4
}

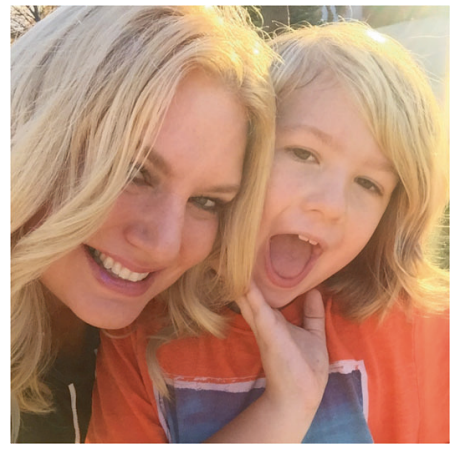

Hirschsprung disease (HD) occurs when nerve cells (also called ganglion cells) are absent from the lower part of the colon. The segment without nerve cells is called the aganglionic segment and it always starts at the bottom of the colon affecting the lower end. It can also extend up the colon, even into the small intestine. The absence of ganglion cells leaves a portion of the colon essentially paralyzed and unable to propel waste products along its length. This is the reason why babies born with HD are often unable to pass their first "meconium" stool and children diagnosed later in life have severe constipation. In addition to having difficulty passing stool, infants and children with HD also typically have abdominal distension and sometimes develop vomiting and loss of appetite.

My son Malachi was born in November 2008. Malachi was born with short segment HD. We had one long terrifying month spent in Intensive Care Unit trying to figure out what exactly was wrong with Malachi. All I knew was that my son was "failing to thrive," a phrase that in other words means we have no clue what is going on. All of which is understandable given the fact that HD only occurs in 1 in 5000 births.

After a biopsy confirmed the diagnosis, Malachi was able to come home. This was the beginning of what I now describe as the Holy "Poop" Chronicles. Malachi required intervention every $4 \mathrm{~h}$ around the clock for the first 6 months consisting of bowel irrigations and dilations to clean his colon. I would love to report that it was a successful outcome but that would be the furthest thing from accurate. As I am not a trained professional in the inner workings of the gastrointestinal tract, I was often unable to thoroughly clean him out and we often landed back where we started in the Children's Hospital battling severe bowel obstructions and infections. This was becoming our norm as we waited for Malachi to have his pull through surgery at 6 months.

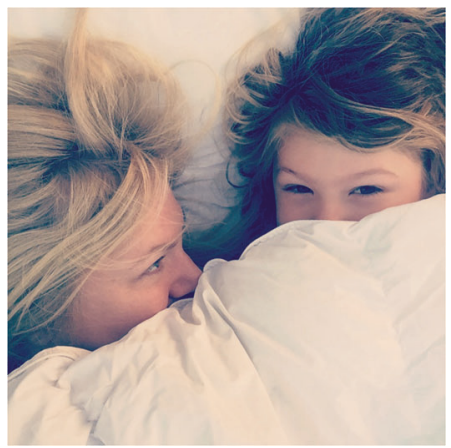

Now I know there is no really any scientific evidence to suggest that severe eczema has anything to do with chronic constipation or bowel obstructions but I stand by that it does. Malachi in addition to the 4-h interventions also had terrible eczema where I did regular wet wrap therapies to hold the eczema at bay (Note: Once Malachi had his pull through surgery and he was passing stool, his eczema cleared). So that was our regular routine for the first 6 months, we were in the trenches.

Phase II, post surgery. Aside from occasional irrigations and some dilations we were for the most part living a somewhat normal life. This is at least what I would call our norm. Then, until about 10 months later when we hit a giant pothole in the road. Another bowel obstruction, then another a few months after that, and as it would turn out nothing was going to plan, my plan of course.

Malachi is now 10 years old and for the most part does well. He still does not have the sensation to pass stool and our lives revolve around his good days and bad days, but we manage. I have come to learn that, with HD, there are no two children alike and that we cannot possibly guess the path of each child. We simply do not understand enough about the disease to know why some children with the same amount of effected colon do exceptionally well while others do not. Do the nerve cells continue to die off after surgery? Are there potentially other parts of the colon effected that we do not see because it is difficult sometimes to get a perfect biopsy? Does diet effect children with HD differently than with non-HD children? Is there additional psychological issues due to the physical and social trauma that then contribute to making a child not want to go to the bathroom?

As a parent and caregiver, I think there is plenty of room to study the different aspects of HD further. I would love to see more

\footnotetext{
${ }^{1}$ Winnipeg, Canada

Correspondence: Elizabeth Crawford (info@pedres.org)
}

Received: 21 February 2019 Accepted: 21 February 2019

Published online: 5 March 2019 
research allocated specifically to the social and psychological impacts of this disease for children aged $\geq 4$ years. I would also like to see studies to identify commonalities that HD patients have with diet, etc.

I am so grateful every day for my son and that he has an overall good quality of life despite having this disease. I started writing a blog about my Malachi's HD journey at https://roosjourney. wordpress.com/ Although I do not blog anymore, because I feel at 10 years it is now Malachi's story to tell, I found blogging to be a helpful therapeutic release during the tough times.

"No one seems to have a definitive answer as to what should happen next. No one can tell me with any certainty an outcome if we decide on doing the surgery. So it's you and me. It's always been that way. Since the moment you were born. You and I have had this unexplainable connection. I would swear you spoke to me. If not in words, I always knew when you were sick. I knew before the doctors that there was something terribly wrong within hours of you being born. I would sense when things would become critical even though you never cried or made a sound before they got worse. So one thing I know for certain as I lay here now staring at the star I wished upon.......you and I will know. We will know and we will do as we always do. Warrior on and I will be forever grateful that I got everything I wished for in you. You are my perfect boy." (Roo's Journey, I Wished Upon A Star) 